Igor Sukhotnik · Iness Miselevich · Michael Lurie Ofer Nativ · Arnold G. Coran · Jorge G. Mogilner

\title{
The time relationship between ipsilateral testicular ischemia and germ cell apoptosis in the contralateral testis in rat
}

Accepted: 11 April 2005 / Published online: 15 July 2005

(C) Springer-Verlag

\begin{abstract}
Unilateral testicular ischemia-reperfusion (IR) in the rat is followed by histologic damage in the contralateral testis, which has been previously explained on immunologic grounds. There is evidence to suggest that apoptosis in the contralateral testis is involved in germ cell loss following IR injury to the testis. We examined the time-dependent effect of testicular ischemia on germ cell apoptosis in the contralateral testis in a rat. Adult Sprague-Dawley rats weighing 250-280 g, were subjected to testicular ischemia for $1,2,3$ or $24 \mathrm{~h}$. Twentyfour hours following onset of the ischemic insult, testes were harvested for immunohistochemical studies. Apoptosis was detected using TUNEL immunohistochemical assay. Testicular ischemia in rats led to histological damage, which was related to the duration of the ischemia. In the contralateral testis, the minimal damage included a decrease in number of germ cell layers, mild disorganization, and single cell apoptosis. Apoptosis in the contralateral testes increased significantly after 2,3 , and $24 \mathrm{~h}$ of ischemia and showed direct, time-related correlation with the duration of ischemia. We conclude that testicular ischemia causes an increase in germ cell apoptosis in the contralateral testis. The extent of apoptosis increases with the duration of the ischemia.
\end{abstract}

I. Sukhotnik $(\varangle) \cdot$ J. G. Mogilner

Department of Pediatric Surgery, Rappaport Faculty of Medicine, Bnai Zion Medical Center, 47 Golomb St, P.O.B. 4940, Haifa 31048, Israel

E-mail: igor-dr@internet-zahav.net

Tel.: +972-4-8256815

Fax: +972-4-8359620

I. Miselevich · M. Lurie

Department of Pathology, Rappaport Faculty of Medicine, Bnai Zion Medical Center, Haifa, Israel

O. Nativ

Department of Urology, Rappaport Faculty of Medicine, Bnai Zion Medical Center, Haifa, Israel

A. G. Coran

Section of Pediatric Surgery C.S. Mott Children's Hospital, University of Michigan Medical School, Ann Arbor, MI, USA
Keywords Testis $\cdot$ Ischemia $\cdot$ Germ cells $\cdot$ Apoptosis

\section{Introduction}

The degree of fertility loss in an individual with testicular torsion depends on the extent of the ischemia and the subsequent damage to the contralateral testis. The injury to the contralateral testis following unilateral testicular torsion is controversial. While some investigators have demonstrated a contralateral effect of testicular ischemia or torsion [7,11], other investigators did not support this concept [2, 19]. The mechanism of the injury to one testis following the contralateral testicular ischemia is also a subject of controversy. The following mechanisms have been proposed to explain the contralateral damage: autoimmunization against spermatogonia, decrease in testicular blood flow caused by a reflex sympathetic response, free oxygen radical formation after detorsion, and overproduction of nitric oxide by activated inducible nitric oxide synthase $[4,8,15,16]$.

Apoptosis has recently been shown to regulate germ cell turnover following IR. Apoptosis or programmed cell death is a continuous process of destruction of nonfunctional cells. It is a physiologic or pathologic process whereby the body disposes of unwanted cells by self-destruction and is the most important defense against these damaged cells. A recent evidence suggests that apoptosis in an ischemic testis increases significantly following IR [20]. However, the role of apoptosis in the reduction of germ cell mass in the contralateral testis is unknown. Enhanced apoptosis may be responsible for torsion-induced germ cell loss; thus, prevention of cell apoptosis may have important implications for therapeutic attempts to reduce or prevent infertility following testicular IR.

The purpose of the present study is to evaluate the time relationship between testicular ischemia and germ cell apoptosis in the contralateral testis in rat. 


\section{Materials and methods}

Male Sprague-Dawley rats, weighing 250-280 g, were divided randomly into five groups of eight to ten rats each: group A-Sham operated animals; group B,C,D and $\mathrm{E}$ included rats, which underwent 1, 2, 3 or $24 \mathrm{~h}$ of unilateral testicular ischemia, respectively.

The animals were housed under standardized conditions ( $12 \mathrm{~h}$ light-dark cycle, controlled room temperature) for 5-7 days. Following an overnight fast, the animals were anaesthetized with an intraperitoneal injection of pentobarbital $(45 \mathrm{mg} / \mathrm{kg})$. Group A control rats underwent incision and closure of the left hemiscrotum. In group B, the left scrotum was incised, the vascular bundle of the testis was isolated, and its clamping for $1 \mathrm{~h}$ caused ischemia. The testis was covered with warm moist dressing to prevent hypothermia. At the end of the ischemic period, the clamp was removed; the ischemic testis was immersed in warm saline and returned to the scrotum. Skin wound was closed using three to zero silk sutures. Group C and group D rats underwent the same procedure, but ischemia was continued for 2 and $3 \mathrm{~h}$, respectively. In group E, the vascular bundle of the testis was isolated and divided between two silk $5 / 0$ sutures and the testis was returned to the scrotum. Animals were killed $24 \mathrm{~h}$ following operation. Both testes were removed, washed with cold saline and dried. Tissue samples from both testes were fixed in $10 \%$ formalin, and embedded in paraffin. Deparaffinized, $5 \mu \mathrm{m}$-sized sections were stained with hematoxylin and eosin. Histological alterations were studied using a graded eye piece at ten times magnification. Johnsen criteria [5] were used to categorize the spermatogenesis using a score of 1-10. In addition, the number of germinal epithelial layers was counted in the five seminiferous tubules as a measure of spermatogenesis [13]. Separation of germ cells from the basement membrane was graded as mild when presents in less than $25 \%$ of seminiferous tubules, as moderate when seen in $25-50 \%$ of tubules, and severe when observed in over $50 \%$ of tubules. The number of apoptotic cells and giant cells in the ischemic testes was graded according to the percentage of involved cells as described by Nambirajan [12].

\section{Measurement of apoptosis}

Serials $-5 \mu \mathrm{m}$ thick paraffin-embedded sections were prepared to establish the degree of apoptosis. The TUNNEL assay for apoptotic cell detection was performed using I.S. Cell Death Detection kit (Boehringer Mannheim GmbH, Mannheim, Germany). For each group, the number of stained germ cells was counted. The apoptotic index AI-1 was defined as the number of apoptotic TUNEL-positive cells per 100 tubules and AI2 as the number of tubules containing apoptotic cells per 100 tubules. Pathologists blinded to the source of testicular tissue performed all measurements.

\section{Statistical analysis}

The data are expressed as the mean \pm SEM. Statistical analysis was performed using the nonparametric Kruskal-Wallis ANOVA test, with $\mathrm{P}$ less than 0.05 considered statistically significant.

Table 1 Correlation of the histologic changes of the ipsilateral testis in relation to the duration of ischemia

\begin{tabular}{|c|c|c|c|c|c|}
\hline \multirow[t]{2}{*}{ Histological criteria } & \multicolumn{5}{|l|}{ Treatment groups } \\
\hline & $\begin{array}{l}\text { Sham operation } \\
(n=10)\end{array}$ & $\begin{array}{l}1 \mathrm{~h} \text { of ischemia } \\
(n=8)\end{array}$ & $\begin{array}{l}2 \mathrm{~h} \text { of ischemia } \\
(n=8)\end{array}$ & $\begin{array}{l}3 \mathrm{~h} \text { of ischemia } \\
(n=8)\end{array}$ & $\begin{array}{l}24 \mathrm{~h} \text { of ischemia } \\
(n=8)\end{array}$ \\
\hline Johnsen criteria & $9.5 \pm 0.2$ & $8.9 \pm 0.1^{*}$ & $8.8 \pm 0.2 *$ & $7.0 \pm 0.9 *$ & $2.6 \pm 0.2 *$ \\
\hline Mild & 0 & $5(63 \%)$ & $4(50 \%)$ & $4(50 \%)$ & 0 \\
\hline Moderate & 0 & 0 & $3(38 \%)$ & $2(25 \%)$ & 0 \\
\hline Severe & 0 & 0 & $1(13 \%)$ & $2(25 \%)$ & $8(100 \%)$ \\
\hline \multicolumn{6}{|c|}{ Separation from the basement membrane } \\
\hline Mild & 0 & $3(38 \%)$ & $4(50 \%)$ & $2(25 \%)$ & 0 \\
\hline Moderate & 0 & 0 & $2(25 \%)$ & $3(38 \%)$ & 0 \\
\hline Severe & 0 & $1(13 \%)$ & 0 & $2(25 \%)$ & $6(75 \%)$ \\
\hline \multicolumn{6}{|l|}{ Percentage of apoptotic cells } \\
\hline Grade 1 & 0 & $2(25 \%)$ & $1(13 \%)$ & $4(50 \%)$ & 0 \\
\hline Grade 2 & 0 & $2(25 \%)$ & $1(13 \%)$ & 0 & 0 \\
\hline Grade 3 & 0 & $1(13 \%)$ & $3(38 \%)$ & $2(20 \%)$ & $1(13 \%)$ \\
\hline \multicolumn{6}{|l|}{ Percentage of giant cells } \\
\hline Grade 1 & 0 & $5(63 \%)$ & $3(38 \%)$ & $3(38 \%)$ & 0 \\
\hline Grade 2 & 0 & 0 & $1(13 \%)$ & $1(13 \%)$ & 0 \\
\hline Grade 3 & 0 & 0 & $2(25 \%)$ & $2(25 \%)$ & $3(38 \%)$ \\
\hline
\end{tabular}

Values are mean \pm SEM or number of rats (plus $\%$ of total number)

$* P<0.05$ versus sham operated animals 


\section{Results}

Ipsilateral ischemic testes

Table 1 compares the histological changes in the ischemic testes and in the normal testes (in Sham group) according the duration of ischemia. The sham operated animals had intact germinal epithelium with an average thickness of about six cell layers. The architecture of the seminiferous tubules and interstitium were normal. The damage in the ischemic testes correlated with the duration of the ischemia. Impaired spermatogenesis was present after $1 \mathrm{~h}$ of ischemia (Group B), but occurred mainly in tubules at the periphery of the testis. The mean score and germ cell layer count in this group were significantly lower compared to control rats. Single cell apoptosis and clumps of apoptotic cells were seen in four and one animals, respectively. Spermatogenic destruction occurred in most tubules following 2 -h of ischemia. The testes of this group showed different degrees of disorganization, single cell apoptosis and clumps of apoptotic cells. The testes of six rats disclosed giant cells and those of six animals demonstrated separation of germ cells from the basement membrane. Three hours of ischemia resulted in a more significant damage. Two testes had spermatogonia only (score 3 ), the mean score being lower than in the control animals. Many tubules contained clumps of apoptotic or giant cells. Ninety percent of germinal cells were present, but separated from the basement membrane, leading to exfoliation into the lumen. The testes demonstrated severe germ cell damage after $24 \mathrm{~h}$ of ischemia, the seminiferous tubules containing only Sertoli cells, showing a lower mean score and lower germ cell layer numbers with increased number of necrobiotic, apoptotic, giant cells, and prominent separation from the basement membrane.

\section{Contralateral testes}

Ischemia of the testis did not change significantly the testicular score in the contralateral testis in all experimental groups compared to control animals. However, the number of germ cell layers decreased significantly in all groups compared to sham animals. Mild disorganization, single cell apoptosis and mild separation of germ cells from the basement membrane were also observed in evaluation of the hematoxylin and eosin-stained sections in about $10 \%$ of the animals (Table 2).

Apoptosis in the contralateral testis

Impaired blood supply resulted in increased germ cell apoptosis in the contralateral testes, which first occurred after $1 \mathrm{~h}$ of ischemia (Group B), but achieved statistical significance only following 2 and $3 \mathrm{~h}$ of ischemia (Groups C and D, respectively; Fig. 1). The number of apoptotic cells per 100 tubules increased significantly following two ( $2.6 \pm 0.6$ vs $1.1 \pm 0.3$ TUNEL positive cells/100 tubules, $P<0.05)$ and $3 \mathrm{~h}(2.9 \pm 1.1$ vs $1.1 \pm 0.3$ TUNEL positive cells/100 tubules, $P<0.05)$ of ischemia, compared to the control animals. Similarly, the number of positive tubules was significantly greater in group $C(1.7 \pm 0.2$ vs $0.6 \pm 0.2$ labeled tubules $/ 100$ tubules, $P<0.05)$ and Group D ( $1.8 \pm 0.5$ vs $0.6 \pm 0.2$ labeled tubules $/ 100$ tubules, $P<0.05)$ than in the testes of control animals. There was no difference in apoptotic index between groups $\mathrm{C}$ and $\mathrm{D}$ rats. Clusters of labeled cells were found in some tubules, whereas, other tubules were totally devoid of apoptotic cells (Fig. 2). Ischemia of $24 \mathrm{~h}$ resulted in a marked increase in the number of labeled cells per 100 tubules $(8.2 \pm 3.8$ vs $1.1 \pm 0.3, P<0.05)$ as well as labeled tubules per 100 tubules $(2.8 \pm 0.9$ vs $0.6 \pm 0.2$, $P<0.05)$, compared to the control rats.

Table 2 Correlation of the histologic changes of the contralateral testis in relation to the duration of ischemia

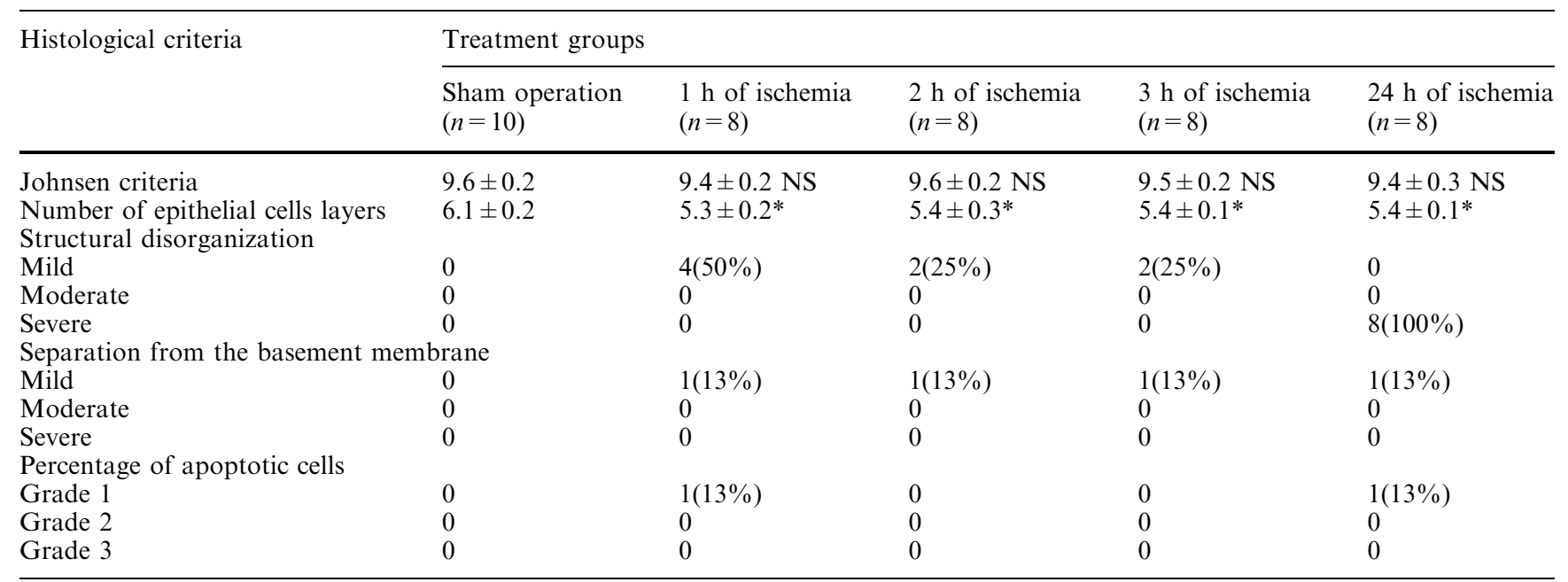

Values are mean $\pm \mathrm{SEM}$ or number of rats (plus $\%$ of total number)

$* P<0.05$ versus sham operated animals 


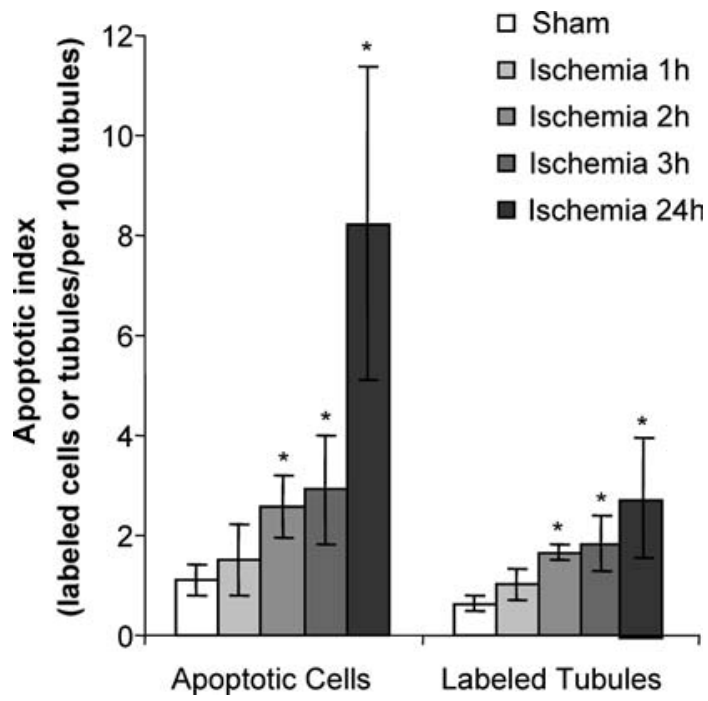

Fig. 1 The time relationship between ipsilateral testicular ischemiareperfusion and germ cell apoptosis in the contralateral testis. Values are mean \pm SEM. ${ }^{*} P<0.05$ versus sham operated animals

Testicular ischemia did not result in Leydig cells apoptosis and Sertoli cells apoptosis in the contralateral testis.

\section{Discussion}

The understanding of testicular physiology and pathology requires knowledge of the regulation of cell death. Modi et al. [14] have shown that germ cell apoptosis is a common event during development of the human gonads. Apoptosis control in the adult testes is crucial for the evolution of normal spermatogenesis. It has been reported that accelerated apoptosis of the primary spermatocytes might partially account for the mechanism of germ cell loss in aging men [6]. Besides its role in normal testicular physiology, apoptosis has been identified as important in the development of a variety of testicular disorders, including undescended testes [18], varicocele [1], and torsion of the testes [20].

Apoptosis has recently been shown to regulate germ cell turnover following IR. The mechanisms responsible for increased apoptosis in the ischemic testes include a production of reactive oxygen species arising from re-perfusing leukocytes [9], stimulation of pro-inflammatory cytokines, secretion of TNF-alpha and IL-1beta [10], activation of nitric oxide synthase [17], and alterations in the mitochondrial respiration [3].
Fig. 2 Histologic sections of contralateral testes in sham operated (a) rats, as well as following $2 \mathrm{~h}(\mathbf{b}), 3 \mathrm{~h}$ (c) and $24 \mathrm{~h}$ (d) of testicular ischemia. Apoptotic cells (arrows) were detected using the terminal deoxyuridine nick-end labeling (TUNEL)

immunohistochemical assay. The number of apoptotic cells increases with duration of ischemia

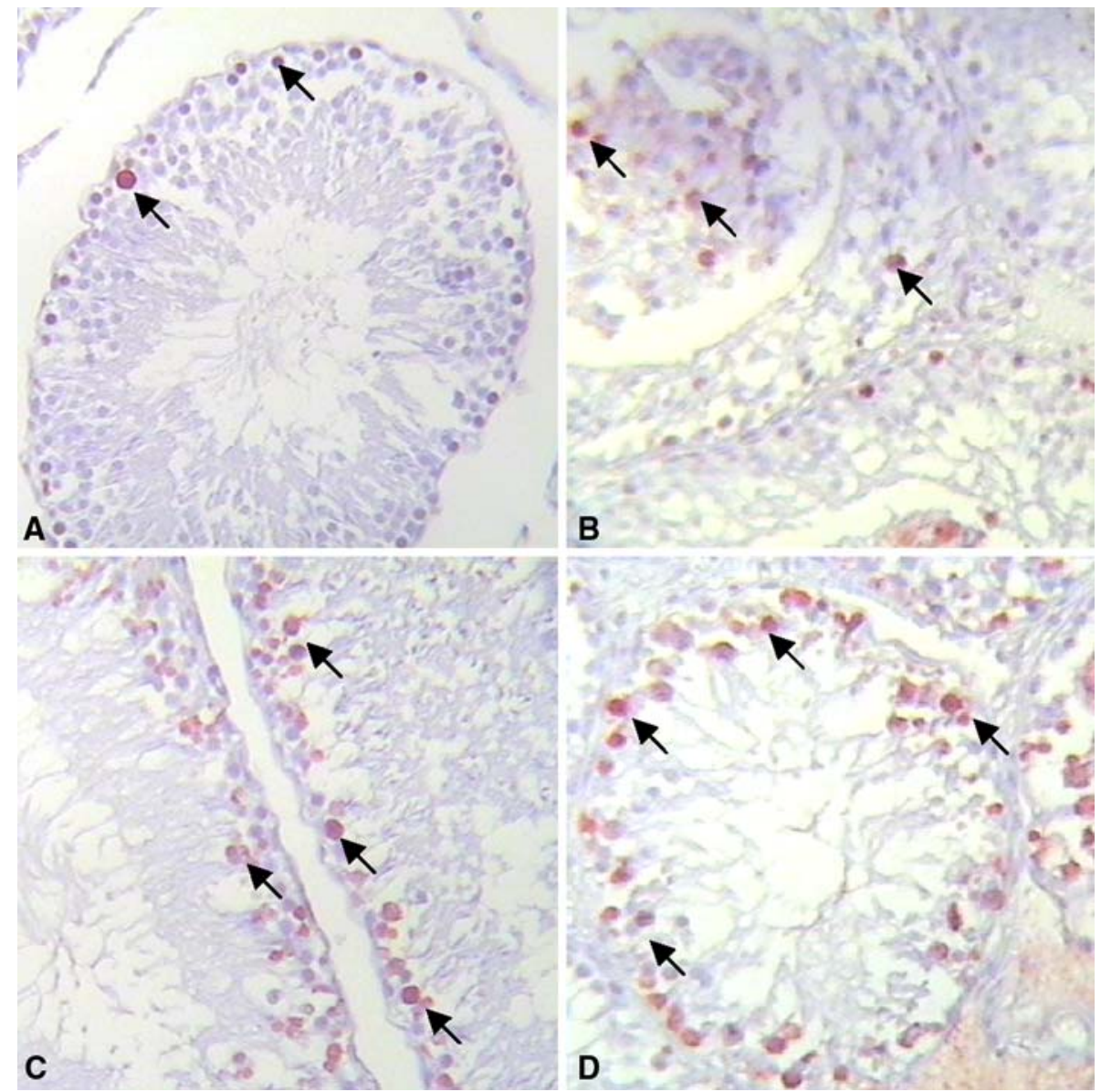


Although the role of ipsilateral apoptosis in germ cell turnover after testicular IR has been reported by several investigators, little is known about the effect of ischemia on apoptosis of the contralateral testes. In these author's experiments, the time-related effect of testicular ischemia on germ cell apoptosis in the contralateral rats' testis was examined. They demonstrated that testicular ischemia in the rat resulted in the damage of ipsilateral testes. Our data demonstrate that testicular ischemia produces minimal contralateral damage, which includes a decrease in the number of germ cell layers, mild disorganization, single cell apoptosis, and mild separation of germ cells from the basement membrane. These data fit with reports of other investigators [2, 19], who also found that ipsilateral torsion did not cause significant contralateral damage. However, the measurement of apoptosis in the contralateral testis demonstrated an increase in germ cell programmed death. There was a direct relationship between the duration of ischemia and the degree of germ cell apoptosis in the contralateral testis. Both the number of apoptotic cells and the number of the tubules containing apoptotic cells firsts increased following $1 \mathrm{~h}$ of ischemia, achieved statistical significance after 2 and $3 \mathrm{~h}$ of ischemia, and reached a peak after $24 \mathrm{~h}$ of ischemia. The mechanism of this effect is unclear. It should be emphasized that the most significant stimulating effect on germ cell apoptosis was observed in group E, in which rats underwent testicular ischemia without reperfusion. As a result, it may be reasonably presumed that stimulation of the synthesis of numerous cytokines, enzymes, and mediators of inflammation in ischemic testis rather than overproduction of oxygen free radicals or other products of reperfusion may induce programmed cell death in the contralateral testis. The present data are consistent with the interpretation that the testicular ischemia results in fertility disturbances, including spermatogenesis arrest and increase in germ cell death via apoptotic pathway in the contralateral testis. We did not study germ-cell apoptosis at different times after testicular IR. Further studies should be done to examine the longer term late changes in the contralateral testis to clarify the mechanisms of fertility loss after testicular torsion

In conclusion, testicular ischemia induces apoptosis in the contralateral testis. Increased duration of ischemia leads to augmented programmed cell death of germ cells. In addition to ischemia-induced cell death in the ischemic testis, increased germ cell apoptosis in the contralateral testis may lead to significant decrease in the germ cell mass and may cause loss of fertility.

\section{References}

1. Barqawi A, Caruso A, Meacham RB (2004) Experimental varicocele induces testicular germ cell apoptosis in the rat. $\mathbf{J}$ Urol 171:501-503

2. Cosentino MJ, Nishida M, Rabinovich R, Cockett ATK (1985) Histological changes occurring in the contralateral testes of prepubertal rats subjected to various duration of unilateral spermatic cord torsion. J Urol 133:906-911

3. Erkkila K, Suomalainen L, Wikstrom M, Parvinen M, Dunke L (2003) Chemical anoxia delays germ cell apoptosis in the human testis. Biol Reprod 69:617-626

4. Harrison RG, Lewis-Jones DI, Moreno de Marval MJ, Connolly RC (1981) Mechanism of damage to the contralateral testis in rats with an ischemic testis. Lancet 2:723-725

5. Johnsen SG (1970) Testicular biopsy score count-a method for registration of spermatogenesis in human testes: normal values and results in 335 hypogonadal males. Hormones 1:2-25

6. Kimura M, Itoh N, Takagi S, Sasao T, Takahashi A, Masumori N, Tsukamoto T (2003) Balance of apoptosis and proliferation of germ cells related to spermatogenesis in aged men. J Androl 24:185-191

7. Krarup T (1978) The testis after torsion. Br J Urol 50:43-46

8. Lewis-Jones DI, Moreno de Marval M, Harrison RG (1982) Impairment of rat spermatogenesis following unilateral experimental ischemia. Fertil Steril 38:482-490

9. Lysiak JJ, Nguyen QA, Turner TT (2002) Peptide and nonpeptide reactive oxygen scavengers provide partial rescue of the testis after torsion. J Androl 23:400-409

10. Lysiak JJ, Nguyen QA, Kirby JL, Turner TT (2003) Ischemiareperfusion of the murine testis stimulates the expression of proinflammatory cytokines and activation of $\mathrm{C}$-jun $\mathrm{N}$-terminal kinase in a pathway to E-selectin expression. Biol Reprod 69:202-210

11. Nagler HM, White RD (1982) The effect of testicular torsion on contralateral testis. J Urol 128:1343-1348

12. Nambirajan L, Agarwala S, Dinda AK, Mitra DK (2002) Fertility and unilateral undescended testis in the rat model III:ultrastructural changes in the contralateral descended testis. Pediatr Surg Int 18:276-280

13. Miller DC, Peron SE, Keck RW, Kropp KA (1990) Effects of hypothermia on testicular ischemia. J Urol 143:1046-1048

14. Modi DN, Sane S, Bhartiya D (2003) Accelerated germ cell apoptosis in sex chromosome aneuploid fetal human gonads. Mol Hum Reprod 9:219-225

15. Sarica K, Kupeli B, Budak M, Kosar A, Kavukcu M, Durak I, Gogus O (1997) Influence of experimental spermatic cord torsion on the contralateral testis in rats. Evaluation of tissue free oxygen radical scavenger enzyme levels. Urol Int 58:208-212

16. Shiraishi K, Naito K, Yoshida K (2001) Nitric oxide promotes germ cell necrosis in the delayed phase after experimental testicular torsion of rat. Biol Reprod 65:514-521

17. Shiraishi K, Yoshida K, Naito K (2003) Activation of endothelial nitric oxide synthase in contralateral testis during unilateral testicular torsion in rats. Arch Androl 49:179-190

18. Tomomasa H, Adachi Y, Oshio S, Umeda T, Irie H, Ishikawa H (2002) Germ cell apoptosis in undescended testis: the origin of its impaired spermatogenesis in the TS inbred rat. Urol 168:343-347

19. Turner TT(1987) On unilateral testicular and epididymal torsion: no effect on the contralateral testis. J Urol 138:1285-1290

20. Turner TT, Tung KS, Tomomasa H, Wilson LW (1997) Acute testicular ischemia results in germ cell-specific apoptosis in the rat. Biol Reprod 57:1267-1274 